\title{
Relationship between maternal and child behaviors in pediatric food allergy - an exploratory study
}

Isolde Sommer, Vivienne Chisholm, Heather Mackenzie, Carina Venter, Taraneh Dean

Parents play an important role in developing young children's food choices. They influence children's eating environments through the foods they make available, their own eating behavior, and the quality of their interactions with children in eating contexts. ${ }^{1}$

In children with food allergies, the development of food habits and preferences takes place in the context of their continuing condition. Mothers often have primary responsibility for the dietary management of their child's allergies in early childhood. ${ }^{2}$ Although few studies have addressed mother-child interactions in the food allergy literature, research in the pediatric chronic illness literature ${ }^{3}$ and in the literature with healthy children ${ }^{4}$ indicate that, in early childhood in particular, developmentally typical feeding difficulties include transient food preferences, picky or fussy eating, and food refusal, which are stressful for parents and a potential cause of interaction difficulties. Collectively these findings point to the importance of redressing the neglect of mother-child interactions in early childhood in the context of food allergies.

Research with non-pediatric populations suggests that an authoritative parenting style (high-demanding, high-responsive) promotes healthy food consumption patterns in children ${ }^{5}$ by providing children with high levels of control and support, and fostering cooperation and self-regulation. ${ }^{6}$ In contrast, authoritarian (high-demanding, low- responsive), permissive (low-demanding, high-responsive), or neglectful (lowdemanding, low-responsive) parenting styles appear to put children at higher risk for becoming overweight or obese. ${ }^{5}$ For pediatric food allergy, a child's cooperation with maternal requests and expectations is particularly important and a positive mother-child interaction style could pave the way for later independent and effective dietary self-management. Thus, this study aimed to compare mother-child interactions of young children with and without food allergies in the context of a novel problem-solving task based on food selection.

Participants were children with and without food allergies (4-8 years old) and their mothers. Children with food allergy and their mothers were recruited through an allergy clinic on the Isle of Wight, United Kingdom. Evidence of IgE- or non-IgE-mediated allergy (positive skin prick test or serum specific IgE results plus a convincing clinical history or a positive food challenge result) to egg, milk, peanuts, tree nuts, sesame, crustaceans, fish, or wheat was required. Mothers and children without food allergies were recruited by advertisement on the university Web site. Children were excluded if they had another condition that affected dietary intake. The Southampton and South West Hampshire National Health Service research ethics committee gave this study ethical approval. 
Initially developed to study mother-child communication in children with diabetes, ${ }^{3}$ a novel collaborative problem-solving activity involving food shopping and classification for the child's birthday party was used to compare mother-child interactions of children with and without food allergies. Instructions for the game are presented in Figure 1.

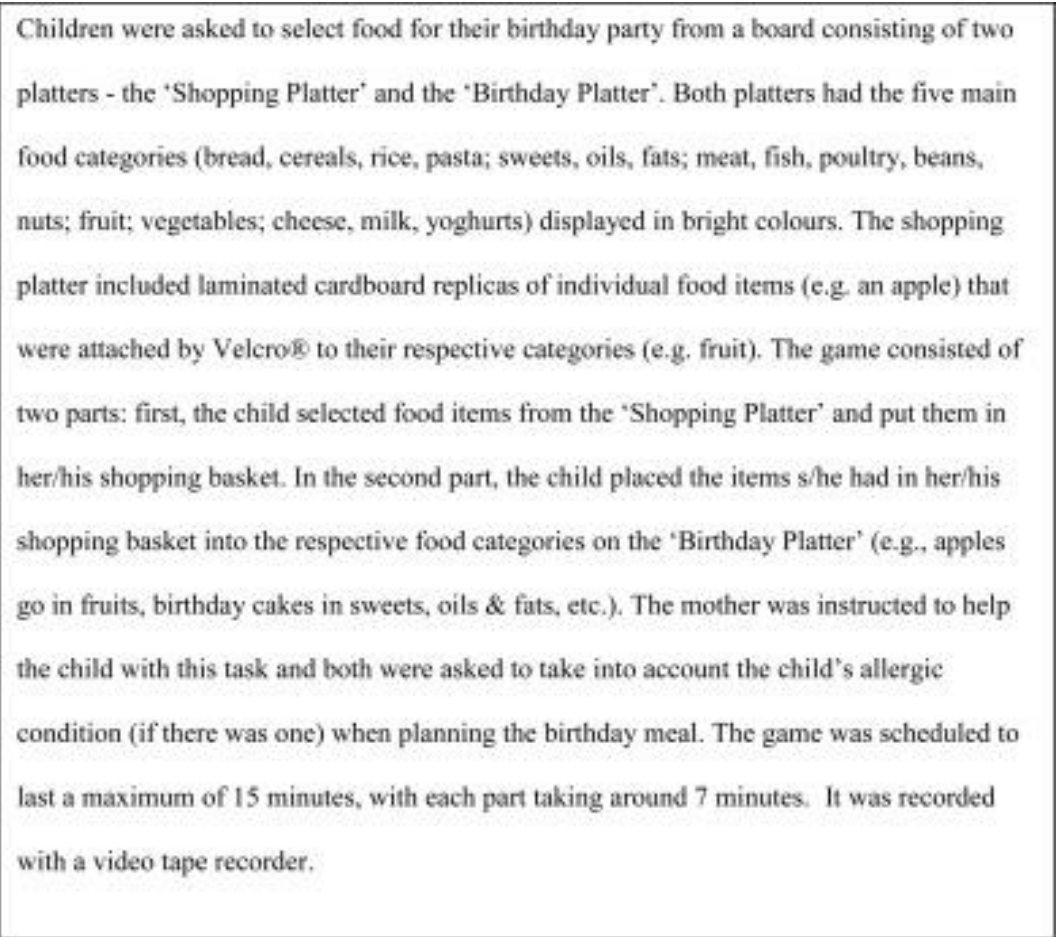

Figure 1. Instructions for the game.

Data were analyzed using qualitative ratings of maternal and child behaviors and frequency counts of verbal and nonverbal maternal behavioral control statements. The mothers' parenting behavior was coded with the Maternal Behavior Rating Scale (MBRS). ${ }^{7}$ This 12 -item scale assesses 4 dimensions of parenting style: responsiveness, affect, achievement orientation, and directiveness. Items include sensitivity to a child's interest, acceptance, warmth, praise, and pace, and are rated on a 5-point Likert-type scale with ratings of 1 reflecting a low incidence of the quality being assessed and ratings of 5 a high incidence. Parenting categories ${ }^{8}$ were defined by dichotomizing the sample on each dimension, with the median as the cutoff to categorize into more authoritarian, authoritative, indulgent, and neglecting parent.

The children's interactive behavior with their mothers was coded using the Child Behavior Rating Scale (CBRS), ${ }^{9}$ which measured 7 global child engagement items: attention, persistence, involvement, cooperation, initiation of activities, joint attention, and affect. Each item also was scored on a scale of 1 to 5 .

Frequencies of verbal and nonverbal maternal behavioral control statements during the food selection process were coded with the behavior commands (eg, "Take the eggs"), soft directives (eg, "Why don't we get some chips?"), and requests (eg, "What would you like?" or "What have you put in your basket?"). The 
key difference among the 3 behaviors is the degree of behavioral control the mother exerts over the child's food choice decisions.

Videotaped observations were coded by the first author and 2 independent raters. Inter-rater agreement was coded according to the formula ([agreements/(agreements + disagreements)] $\times 100) \cdot{ }^{10}$ Average interrater agreement was initially $68 \%$ for the MBRS and $75 \%$ for the CBRS before the 3 raters agreed on final ratings for each item. For the frequency coding of maternal control behavioral events, inter-rater agreement exceeded $85 \%$.

This study included 12 children, 5 with food allergies and 7 without food allergies. Sample characteristics are listed in eTable 1.

For parenting style, no specific pattern for either group emerged. Five mothers used an authoritative parenting style during the activity, 4 an authoritarian style, 2 a neglectful style, and 1 an indulgent style. Four of the 5 children whose mother displayed an authoritative parenting style showed scores above the median with respect to their engagement behavior during the activity.

Likewise, food-allergic and non-food-allergic dyads did not show any differences in their behavior scores (results not presented). Thus, they were combined for further analysis to explore whether there was a relation between maternal and child behaviors that could have clinical relevance for young children with food allergies and their mothers.

The analysis of all 12 dyads indicated that mothers who were able to engage the child in the play interaction (effectiveness), clearly enjoyed interacting with the child (enjoyment), communicated and reacted emotionally toward the child (expressiveness), expressed warmth (warmth), and praised the child (praise) had children who were more willing to cooperate with their requests or suggestions (cooperation), initiated interactions and engaged with them (joint attention), and showed positive affect toward the mother or the activity in general (affect). In contrast, mothers who demonstrated more directiveness toward their children (directiveness) appeared to have children who were less engaged in the activity (all dimensions; Table 1). 
Table 1. Spearman rank correlation coefficients $(\rho)$ for mother-child behaviors

\begin{tabular}{|l|l|l|l|l|l|l|l|}
\hline \multirow{2}{*}{ Mother } & \multicolumn{5}{|l|}{ Child } \\
\cline { 2 - 8 } & Attention & Persistence & Involvement & Cooperation & Initiation & $\begin{array}{l}\text { Joint } \\
\text { attention }\end{array}$ & Affect \\
\cline { 2 - 8 } Sensitivity & 0.403 & 0.004 & 0.446 & 0.455 & -0.165 & 0.264 & 0.376 \\
\hline Responsivity & 0.321 & 0.128 & 0.456 & 0.400 & 0.064 & 0.563 & $0.733^{\mathrm{a}}$ \\
\hline Effectiveness & $0.716^{\mathrm{a}}$ & 0.472 & $0.698^{\mathrm{a}}$ & $0.776^{\mathrm{a}}$ & 0.404 & $0.875^{\mathrm{a}}$ & $0.931^{\mathrm{a}}$ \\
\hline Acceptance & 0.391 & 0.164 & 0.469 & 0.407 & 0.234 & $0.582^{\mathrm{a}}$ & $0.713^{\mathrm{a}}$ \\
\hline Enjoyment & 0.562 & 0.287 & 0.550 & $0.637^{\mathrm{a}}$ & 0.377 & $0.724^{\mathrm{a}}$ & $0.870^{\mathrm{a}}$ \\
\hline Expressiveness & 0.197 & 0.118 & 0.230 & $0.663^{\mathrm{a}}$ & -0.057 & $0.836^{\mathrm{a}}$ & $0.798^{\mathrm{a}}$ \\
\hline Inventiveness & 0.451 & 0.050 & 0.537 & $0.600^{\mathrm{a}}$ & 0.104 & 0.529 & $0.622^{\mathrm{a}}$ \\
\hline Warmth & 0.251 & 0.084 & 0.333 & $0.813^{\mathrm{a}}$ & -0.208 & $0.712^{\mathrm{a}}$ & $0.702^{\mathrm{a}}$ \\
\hline Achievement & 0.079 & -0.180 & 0.049 & 0.416 & -0.134 & 0.250 & 0.260 \\
\hline Praise & 0.296 & 0.138 & 0.323 & $0.596^{\mathrm{a}}$ & 0.071 & $0.800^{\mathrm{a}}$ & $0.815^{\mathrm{a}}$ \\
\hline Directiveness & -0.115 & -0.532 & -0.181 & -0.079 & -0.264 & 0.032 & -0.207 \\
\hline Pace & -0.157 & 0.030 & -0.029 & 0.157 & -0.175 & 0.173 & 0.029 \\
\hline
\end{tabular}

a $P<.05(n=12)$ for all mother-child dyads combined; mean scores of maternal and child behavior ratings were calculated for correlational analysis; $\rho=0.60-0.79$ indicates a "strong" and $\rho=0.80-1.0$ a "very strong" relation between maternal and child behaviors.

To investigate this trend with respect to the child's allergic condition, direct counts of maternal control behaviors during the food selection process were performed. Mothers of children with food allergies showed on average a proportionally higher use of commands ( $18 \%$ vs $7 \%$ ) and soft directives ( $25 \%$ vs $8 \%$ ) than mothers of children without allergies and they were less likely to utter requests ( $57 \%$ vs $85 \%$ ). This study concurs with previous research on mothers and their young children with type 1 diabetes $^{[3]}$ and $[11]$ in indicating that the novel approach presented shows promise as a technique for exploring mother-child interactions in young children with food allergy. This approach not only has potential for use as a behavioral assessment tool in clinical settings but can also contribute to future research concerning behavioral aspects of dietary management in young children with food allergies and their parents, especially in combination with complementary research approaches. Results suggest that independent of the allergic condition, mothers who display an authoritative parenting style are more likely to encourage their children to produce high levels of cooperation and positive affect. Such a parenting style could lay the foundation for a favorable relationship toward food by granting children self-regulation and support instead of overprotection and control in relation to their food allergy management. Study limitations include a small sample and findings based on correlational analyses, which preclude insight into causality. These factors limit the generalizability and conclusiveness of our findings. However, although the 
findings are of exploratory nature, they could initiate more large-scale research aiming to understand how mother-child interactions in the context of food might influence the long-term management of food allergies in childhood and adulthood.

\section{Acknowledgments}

We thank Jackie Hillman for assistance with data analysis.

\section{Supplementary Data}

eTable 1. Characteristics of children

\begin{tabular}{|l||l|l|}
\hline & With food allergy $(\mathrm{n}=5)$ & Without food allergy $(\mathrm{n}=7)$ \\
\hline Mean age $(\mathrm{y})$ & 5.6 & 5.1 \\
\hline Sex, $\mathrm{n}$ & & \\
\hline Girls & 3 & 5 \\
\hline Boys & 2 & 2 \\
\hline Maternal education, $\mathrm{n}$ & & \\
\hline GCSE or A level & 5 & 3 \\
\hline Degree level & 0 & 1 \\
\hline Postgraduate degree level & 0 & 3 \\
\hline Paternal education, $\mathrm{n}$ & & \\
\hline GCSE or A level & 3 & 3 \\
\hline Degree level & 1 & 2 \\
\hline Postgraduate degree level & 0 & 2 \\
\hline Ethnicity, $\mathrm{n}$ & & \\
\hline White British & 2 & 7 \\
\hline Black British & 1 & 0 \\
\hline Asian British & 1 & 0 \\
\hline Mixed background & 1 & 0 \\
\hline Type of diet, $\mathrm{n}$ & & \\
\hline Omnivore & 5 & 7 \\
\hline Vegetarian & 0 & \\
\hline Culprit foods, $\mathrm{n}$ & & \\
\hline Peanuts & 2 & \\
\hline Tree nuts & 1 & \\
\hline Milk & 2 & \\
\hline Eggs & 0 & \\
\hline Wheat & & \\
\hline Avoidance, $\mathrm{n}$ & & \\
\hline Single foods & & \\
\hline Multiple foods & & \\
\hline Ab & & \\
\hline
\end{tabular}

Abbreviation: GCSE, General Certificate of Secondary Education. 


\section{References}

G.L. Mitchell, C. Farrow, E. Haycraft, C. Meyer Parental influences on children's eating behaviour and characteristics of successful parent-focused interventions Appetite, 60 (2013), pp. 85-94

D. Mandell, R. Curtis, M. Gold, S. Hardie Anaphylaxis: how do you live with it? Health Soc Work, 30 (2005), pp. 325-335

V. Chisholm, L. Atkinson, C. Donaldson, K. Noyes, A. Payne, C. Kelnar Maternal communication style, problem-solving and dietary adherence in young children with type 1 diabetes Clin Child Psychol Psychiatry, 16 (2011), pp. 443-458

S. Carnell, L. Cooke, R. Cheng, A. Robbins, J. Wardle Parental feeding behaviours and motivations. A qualitative study in mothers of UK pre-schoolers Appetite, 57 (2011), pp. 665-673

E.F. Sleddens, S.M. Gerards, C. Thijs, N.K. de Vries, S.P. Kremers General parenting, childhood overweight and obesity-inducing behaviors: a review Int J Pediatr Obes, 6 (2011), pp. e12-e27

K. Rhee Childhood overweight and the relationship between parent behaviors, parenting style, and family functioning Ann Am Acad Pol Soc Sci, 615 (2008), pp. 11-37

Mahoney G. The Maternal Behavior Rating Scale-Revised. Available from the author; 2008.

Maccoby E, Martin J. Socialization in the context of the family: parent-child interaction. In: Handbook of Child Psychology, Volume 4: Socialization, Personality, and Social Development, EM Hetherington, ed. New York: Wiley; 1983, pp 37-51.

G. Mahoney, C. Wheeden Effects of teacher style on the engagement of preschool aged children with special learning needs J Dev Learn Disord, 2 (1998), pp. 293-315

R. Bakeman, J.M. Gottman Observing Interaction-An Introduction to Sequential Analysis (2nd ed.) Cambridge University Press, Cambridge (1997)

V. Chisholm, L. Atkinson, L. Bayrami, K. Noyes, A. Payne, C. Kelnar An exploratory study of positive and incongruent communication in young children with type 1 diabetes and their mothers Child Care Health Dev, 40 (2014), pp. 85-94 
Disclosures: Authors have nothing to disclose.

Funding Sources: This study was funded by a studentship of the University of Portsmouth. 